\title{
Is There an Association Among Actual Motor Competence, Perceived Motor Competence, Physical Activity, and Sedentary Behavior in Preschool Children?
}

\author{
Vitor Lopes \\ Polytechnic Institute of Bragança \\ Lisa Barnett \\ Deakin University

\section{Luís Rodrigues} \\ Polytechnic Institute of Viana do Castelo
}

\begin{abstract}
The purpose is to explore relationships among moderate to vigorous physical activity (MVPA), sedentary behavior (SB), and actual gross motor competence (MC) and perceived motor competence (PMC) in young children. Data were collected in 101 children $(M$ age $=4.9 \pm 0.93$ years $)$. MVPA was measured with accelerometry. Gross MC was assessed with the Portuguese version of the Movement Assessment Battery for Children. PMC was evaluated with the Pictorial Scale of Perceived Competence and Social Acceptance for Young Children. Regressions were used to determine predictive relationships related to the following research questions: (a) Can gross $\mathrm{MC}$ predict perceived motor competence, (b) can actual and perceived gross MC predict MVPA, and (c) can actual and perceived gross MC predict SB? Results showed no association between gross MC and PMC and between these constructs and MVPA and SB. This lack of association in the early ages is probably due to the young children's cognitive inability to make accurate self-judgments and evaluations. A child might have low levels of actual gross MC but perceive her- or himself as skillful.
\end{abstract}

Keywords: motor development, motor performance, coordination

Motor competence can be conceptualized as a person's ability to execute different motor acts, including coordination of both fine (e.g., manual dexterity) and gross (e.g., static and dynamic balance) motor skills (Henderson, Sugden, \& Barnett, 2007). Stodden et al. (2008) have conceptualized a model in which gross

Lopes is with the Polytechnic Institute of Bragança, Campus de Santa Apolónia, Bragança, Portugal. Barnett is with Deakin University, Melbourne, Victoria, Australia. Rodrigues is with the Polytechnic Institute of Viana do Castelo, Viana do Castelo, Portugal. Address author correspondence to Vitor Lopes at vplopes@ipb.pt 
motor competence is in a cyclical and reciprocal relationship with physical activity (PA). Higher skilled children engage in more PA, and this engagement in PA in turn leads to greater gross motor competence, resulting in more likelihood of a healthy weight status. The reverse is true for low-skilled children (Stodden et al., 2008).

A systematic review of 21 articles showed evidence that supports the model assumption that children of all ages with less gross motor competence are also less active (Lubans, Morgan, Cliff, Barnett, \& Okely, 2010). Although most evidence is cross-sectional (Lubans et al., 2010), some longitudinal evidence has suggested that children who are motor competent are more active (Barnett, van Beurden, Morgan, Brooks, \& Beard, 2009; V.P. Lopes, Rodrigues, Maia, \& Malina, 2011) and fit (Barnett, Morgan, van Beurden, \& Beard, 2008) in subsequent years.

The aforementioned model (Stodden et al., 2008) also incorporates perceived motor competence. Higher skilled children are hypothesized to develop more accurate self-perception, and this enables more PA engagement, leading to greater gross motor competence (Stodden et al., 2008). These relationships are seen to increase in strength as children age (Stodden et al., 2008), and this is evident in the literature. A recent systematic review found perceived motor competence had the strongest relationship to PA compared with other aspects of self-concept and that age positively moderated the relationship (Babic et al., 2014). For example, positive cross-sectional associations between perceived motor competence and actual gross motor competence have been demonstrated in adolescence (Barnett, Morgan, van Beurden, Ball, \& Lubans, 2011) and late childhood (Vedul-Kjelsås, Sigmundsson, Stensdotter, \& Haga, 2012). In younger children, there is some evidence of perceived motor competence and actual gross motor competence associations (Barnett, Ridgers, \& Salmon, 2015; Robinson, 2011), although one study in young children reported no association (Spessato, Gabbard, Robinson, \& Valentini, 2013).

A knowledge gap exists regarding the relationship of sedentary behavior to gross motor competence and perceived motor competence. Sedentary behavior is defined as activities that do not increase energy expenditure substantially above the resting level ( $<1.5 \mathrm{METs})$, such as sleeping, sitting, lying down, and watching television or other forms of screen-based entertainment (Pate, O'Neill, \& Lobelo, 2008). A recent systematic review of sedentary behavior and health indicators in children ages 0-4 years found no studies reported on motor competence (LeBlanc et al., 2012). One study in young children found no association (Cliff, Okely, Smith, \& McKeen, 2009), whereas in older children, one study found significant negative associations between sedentary behavior and gross motor competence (Wrotniak, Epstein, Dorn, Jones, \& Kondilis, 2006).

Thus, it appears in older children that there is an established relationship between gross motor competence, perceived motor competence, and PA and an unknown relationship between sedentary behavior and these variables resulting from the lack of studies. However, in young children the relationship is less clear. On the basis of the existing data, we believe the associations between perceived motor competence, gross motor competence and PA-sedentary behavior are incipient or nonexistent at the preschool age (3-5 years). This is because, at this age, children's gross motor competence is at a crucial developmental phase but far away from being consolidated. That results in children demonstrating weak, inconsistent levels of gross motor competence (Goodway \& Smith, 2005). At the same time, 
young children demonstrate limited accuracy in perceiving their gross motor competence and usually show exaggerated levels of perceived motor competence relative to reality (Goodway \& Rudisill, 1997; Harter, 1999), coupled with a high interest in PA participation. Thus, according to the Stodden et al. (2008) model, we hypothesize that the relationship between PA-sedentary behavior, gross motor competence, and perceived motor competence at this early age is still of a weak magnitude and difficult to demonstrate, but somewhere in the developmental years it should be possible to identify the age-related moment where this relationship starts to emerge.

The purpose of this study was therefore to explore the possible relationships between moderate to vigorous PA, sedentary behavior, and actual and perceived gross motor competence in young children in an attempt to identify the developmental appearance of this well-described phenomenon. The specific research questions were at this early age (a) can gross motor competence predict perceived motor competence, (b) can actual and perceived gross motor competence predict moderate to vigorous PA, and (c) can actual and perceived gross motor competence predict sedentary behavior? Our prediction, as described in the Stodden et al. (2008) model, is that there will be weak or no associations among these variables at this early age.

\section{Method}

\section{Participants}

Two preschools were approached as a convenience sample, and both agreed to participate. Permission was obtained from the respective director, and parents or guardians gave informed consent. The children did not formally assent, but if a child indicated that she or he did not want to participate, he or she did not have to. A total of 101 children (48 girls, $47.5 \%$; 53 boys, $52.5 \%)$ ages $3-5$ years $(M=$ $4.7 \pm 0.84$ years) consented. Three refusals resulted in a $97.4 \%$ participation rate, and all children completed all assessments. This study was approved by the ethics committee of the institution of the first author.

All children were evaluated in the preschool they attended. Trained technicians, supervised by one of the researchers, tested the participants. Children were assessed inside a school room one at a time, first with the perceived motor competence test and then with the gross motor competence test.

\section{Physical Activity}

PA was measured by accelerometry with the ActiGraph GT3X (ActiGraph Corp., Pensacola, FL) that uses a solid-state triaxial accelerometer. In this study, only the vertical axis was used because the cut-points used were determined on the basis of accelerometer counts from the vertical axis.

Participants were instructed to wear the accelerometer during waking hours on the right hip for 7 consecutive days and to remove the accelerometer during activities in which water was involved. Parents also received detailed instructions and ensured the correct use of the accelerometer by children. Accelerometers express PA in counts and were initialized to capture the frequency of these counts every 
15 s (i.e., epochs). Only measurements with at least 3 valid days (at least 8 hr) were considered (all children met this criterion). Periods of 10 consecutive minutes of no accelerometry counts were considered to be nonwearing time (Cain, Sallis, Conway, Dyck, \& Calhoon, 2013). On the basis of the suggestions of Janssen et al. (2013) we used the 25 counts $15 \mathrm{~s}^{-1}$ or fewer as the sedentary behavior threshold and 420 counts $15 \mathrm{~s}^{-1}$ or more as the moderate to vigorous PA threshold. Total minutes per day in sedentary behavior and moderate to vigorous PA were summed to obtain the time per day in sedentary behavior and moderate to vigorous PA. Accelerometer data were screened and scored with the ActiLife software program Version 6 (ActiGraph Corporation, Pensacola, FL).

\section{Somatic Measures}

Height and weight were measured using a stadiometer and a scale according to standardized procedures (Eston \& Reilly, 2001) to calculate PA intensity. Values were recorded to the nearest $0.1 \mathrm{~cm}$ and $100 \mathrm{~g}$, respectively. Body mass index was calculated as body weight (in kilograms), divided by height (in meters) squared. Weight status was classified according to International Obesity Task Force cutoff values for body mass index (Cole, Bellizzi, Flegal, \& Dietz, 2000; Cole, Flegal, Nicholls, \& Jackson, 2007).

\section{Gross Motor Competence}

Gross motor competence was assessed with the Movement Assessment Battery for Children, Second Edition (MABC-2; Henderson et al., 2007). The MABC-2 was designed to identify and describe impairments in the motor function of children and is one of the most used measures in both clinical and research settings (Schulz, Henderson, Sugden, \& Barnett, 2011). The MABC-2 consists of eight tasks designed for three age bands (3-6, 7-10, and 11-16 years old), incorporating three areas: manual dexterity, ball skills, and static and dynamic balance. The tasks and scoring procedures for Age Band 1 (3-6 years old) were used for participants in this study. Ball skills included aiming and catching. The aiming task requires the child to throw a beanbag to a target mat. The catching task requires children to catch a beanbag tossed by a researcher. Balance tasks include walking with heels raised, a one-leg balance, and jumping. Manual dexterity data were not used for this study, because our interest was gross motor competence. The child's performance on each of these tasks (a score for either accuracy or completion time) were summed, producing area scores, and converted to normative scores (age adjusted) according the MABC-2 test manual (Henderson et al., 2007).

\section{Perceived Competence}

Perceived competence was evaluated with the Portuguese version (Ducharne, 2004) of the Pictorial Scale of Perceived Competence and Social Acceptance for Young Children (PSPCSA) (Harter \& Pike, 1984). This version contains 31 items, 23 of which are the same as the original scale. The 31 items load on four factors: acceptance (relationship with mother and relationship with peers), and perceived competence (on tasks/activities naturally learned by the children and tasks/activities 
intentionally taught to the children by parents and teachers). For this study only the perceived competence items were of interest.

The administration method consisted of presenting two illustrations for each item, typically, a child who is very good at the task(s) and a child who is not very good at the task(s). The child is read two brief statements, one positive and one negative, for each of the pictures (e.g., participant would be told that one girl/boy is good at climbing but the other girl/boy is not very good at climbing). The child is then asked to choose which of the children from the two statements is most like him or her, the child depicting the positive statement or the child depicting the negative statement. After the respondent identifies with one of the children, the interviewer asks whether she/he is 'a lot like' that child or 'a little like' that child. Each item is scored on a 4-point scale, where 4 represents the highest degree of perceived acceptance or competence.

The psychometric qualities of the Portuguese version of Pictorial Scale of Perceived Competence and Social Acceptance for Young Children are considered very acceptable, Cronbach's alpha for internal consistency for the 31 items was .87 and varies between .68 and .82 for the subscales (Ducharne, 2004). Only the motor items (as opposed to cognitive items) from both perceived competence subscales were summed to form a perceived motor competence index. The eight items included were "Good at swinging," "Good at climbing," "Good at skipping," "Good at running," "Good at hopping," "Is strong," "Playing with a ball/dribbling," and "Can tie shoes."

\section{Data Analysis}

Descriptive statistics (means and standard deviation) were calculated for moderate to vigorous PA, sedentary behavior, gross motor competence, and perceived motor competence. Collected data were checked for normality. Mann-Whitney $U$ tests were used to assess any significant differences between boys and girls. Spearman correlations were calculated between moderate to vigorous PA, sedentary behavior, gross motor competence, and perceived motor competence. After log transforming some variables to achieve normality distributions and testing for linearity and homoscedasticity, several regression models were tested with perceived motor competence, moderate to vigorous PA, and sedentary behavior as outcome variables. Age (decimal age) and sex were controlled for in the moderate to vigorous PA and sedentary behavior models. The differences in moderate to vigorous PA and sedentary behavior between children within the first and fourth quartiles of motor competence and perceived motor competence were also tested with Mann-Whitney $U$. All $p$ values were considered significant at $p<.05$.

\section{Results}

Descriptive statistics (means and standard deviations) are shown in Table 1. Table 2 displays the percentage of boys and girls who scored within each quartile of motor competence (ball skills and balance).

According to International Obesity Task Force cutoff values for body mass index (Cole et al., 2000, 2007), 3.5\% of children sample were overweight and $7.8 \%$ were obese. 
Table 1 Descriptive Statistics $(M \pm S D)$ and Results for the Difference Between Boys and Girls (Mann-Whitney $U$ test)

\begin{tabular}{lcc}
\hline & \multicolumn{2}{c}{$\boldsymbol{M} \pm \mathbf{S D}$} \\
\cline { 2 - 3 } Characteristic & Girls & Boys \\
\hline Age (yr) & $4.8 \pm 0.8$ & $4.7 \pm 0.8$ \\
Height (cm) & $19.9 \pm 4.6$ & $19.9 \pm 3.9$ \\
Weight (kg) & $108.8 \pm 7.8$ & $110.1 \pm 7.2$ \\
BMI & $16.5 \pm 2.1$ & $16.3 \pm 1.9$ \\
Gross motor competence & & \\
$\quad$ Balance & $10 \pm 2$ & $11 \pm 3$ \\
$\quad$ Ball skills & $11 \pm 3$ & $12 \pm 3$ \\
Perceived motor competence & $3.1 \pm 0.6$ & $3.3 \pm 0.5$ \\
Physical activity & & \\
$\quad$ SB (min/day) & $341.6 \pm 47.5$ & $325.9 \pm 52.5$ \\
$\quad$ MVPA (min/day)* & $86.5 \pm 28.6$ & $110.4 \pm 29.2$ \\
\hline
\end{tabular}

*Significant at $p<.01 . \mathrm{BMI}=$ body mass index; MVPA = moderate to vigorous physical activity; $\mathrm{SB}$ $=$ sedentary behavior.

Table 2 Percentage of Girls and Boys Who Scored Within Each Quartile on Balance and Ball Skill Motor Competence

\begin{tabular}{lccccc}
\hline & \multicolumn{2}{c}{ Girls, \% } & & \multicolumn{2}{c}{ Boys, \% } \\
\cline { 2 - 3 } \cline { 5 - 6 } Quartile & Ball skills & Balance & & Ball skills & Balance \\
\hline First & 20.0 & 20.0 & & 18.5 & 18.5 \\
Second & 40.0 & 40.0 & & 41.5 & 41.5 \\
Third & 24.0 & 24.0 & & 18.5 & 18.5 \\
Fourth & 16.0 & 16.0 & & 21.5 & 21.5 \\
\hline
\end{tabular}

According to the normative values of the MABC-2, the majority of boys and girls were within the second quartile in both ball skills and balance. The mean values for each perceived motor competence item, which could vary between 1 and 4 , are situated slightly above 3 for both boys and girls, meaning they tend to perceive themselves as somewhat positive. The mean values for moderate to vigorous PA indicate that both boys and girls were, in general, quite active, although boys were significantly more active than girls. There were no significant differences between boys and girls in sedentary behavior.

Table 3 shows the correlations between moderate to vigorous PA and gross motor competence (balance and ball skills), perceived motor competence, and sedentary behavior items. All correlations were inexistent or very low, with only the correlation between perceived motor competence and balance positive and significant. 
Table 3 Spearman Correlations Between Moderate to Vigorous Physical Activity and Gross Motor Competence (Balance and Ball Skills), Perceived Motor Competence, and Sedentary Behavior Items

\begin{tabular}{lccccc}
\hline Variables & $\mathbf{1}$ & $\mathbf{2}$ & $\mathbf{3}$ & $\mathbf{4}$ & $\mathbf{5}$ \\
\hline 1. Balance & - & & & & \\
2. Ball skills & - & - & & & \\
3. PMC & $.19^{*}$ & .17 & - & & \\
4. SB & .15 & .03 & .05 & - & \\
5. MVPA & -.07 & -.05 & .15 & - & - \\
\hline
\end{tabular}

*Significant at $p<.05$. MVPA = moderate to vigorous physical activity; $\mathrm{PMC}=$ perceived motor competence; $\mathrm{SB}=$ sedentary behavior.

Tables 4-6 show the results of the regression models for gross motor competence (ball skills and balance), moderate to vigorous PA, and sedentary behavior. The predictor variables in each case are not significant. Ball skills approached significance $(p=.052)$ in the first model, in which perceived motor competence is the outcome.

The results of the Mann-Whitney $U$ for the differences in moderate to vigorous PA and sedentary behavior between children within the first and fourth quartile of motor competence and perceived motor competence were all nonsignificant.

\section{Discussion}

The aim of this study was to determine the relationship between moderate to vigorous PA, sedentary behavior, perceived motor competence, and gross motor competence in young children (ages 3-6 years). Boys and girls had similar results in perceived motor competence and gross motor competence, but boys were more active than girls, with significantly more time in moderate to vigorous PA. As we expected, and as the Stodden et al. (2008) model predicts, there was little relationship between gross motor competence, perceived motor competence, sedentary behavior, and PA. There was no association between moderate to vigorous PA and gross motor competence (balance and ball skills), perceived motor competence, and sedentary behavior items, with only the correlation between gross motor competence in balance skills and perceived motor competence significant (but low).

With reference to perceived motor competence and gross motor competence, previous findings have been mixed. In contrast to this study, Barnett, Ridgers, and Salmon (2015) found a positive association between perceived motor competence and gross motor competence in slightly older children (ages 4-8 years). In children of similar age (4 years) to those in the current study, Robinson (2011) found a moderate correlation (.28-.51), and LeGear et al. (2012) also found a modest relationship between perceptions of competence and motor competence (.17-.22). However, similar to this study, other authors also found no significant association between these factors in young children (e.g., Spessato et al., 2013). 
Table 4 Regression Analysis for Perceived Motor Competence

\begin{tabular}{lcccc}
\hline Predictors & $\boldsymbol{F}$ & $\boldsymbol{R}^{2}$ & $\boldsymbol{t}$ & $\boldsymbol{p}$ \\
\hline Model & 4.57 & .38 & & .002 \\
Age & & & 2.56 & .012 \\
Sex & & 1.35 & .178 \\
Balance & & & 1.52 & .132 \\
Ball skills & & & 1.91 & .052 \\
\hline
\end{tabular}

Table 5 Regression Analysis for Moderate to Vigorous Physical Activity: Two Models

\begin{tabular}{lcccc}
\hline Model and Predictors & $\boldsymbol{F}$ & $\boldsymbol{R}^{\mathbf{2}}$ & $\boldsymbol{t}$ & $\boldsymbol{p}$ \\
\hline Model 1 & 5.48 & .18 & & .002 \\
PMC & & & 0.67 & .501 \\
Age & & & -1.72 & .088 \\
Sex & & & 3.02 & .003 \\
Model 2 & 4.48 & .19 & & .003 \\
Ball skills & & & -0.81 & .421 \\
Balance & & & .02 & .982 \\
Age & & & 1.95 & .054 \\
Sex & & & 3.39 & .001 \\
\hline
\end{tabular}

Note. Model 1 includes PMC as a predictor; Model 2 includes MC as a predictor. MC = gross motor competence; $\mathrm{PMC}=$ perceived motor competence.

Table 6 Regression Analysis for Sedentary Behavior: Two Models

\begin{tabular}{lcccc}
\hline Model and Predictors & $\boldsymbol{F}$ & $\boldsymbol{R}^{2}$ & $\boldsymbol{t}$ & $\boldsymbol{p}$ \\
\hline Model 1 & 5.02 & .17 & & .003 \\
PMC & & & -0.79 & .427 \\
Age & & & 3.74 & $>.001$ \\
Sex & & & -1.59 & .116 \\
Model 2 & 5.288 & .22 & & .001 \\
Ball skills & & & -0.31 & .754 \\
Balance & & & 1.88 & .063 \\
Age & & & 4.18 & $>.001$ \\
Sex & & & -1.96 & .053 \\
\hline
\end{tabular}

Note. Model 1 includes PMC as a predictor; Model 2 includes MC as a predictor. $\mathrm{MC}=$ gross motor competence; $\mathrm{PMC}=$ perceived motor competence. 
This tendency toward a lack of association or a modest association in the early ages is probably the result of young children's cognitive inability to make accurate self-judgments and evaluations (Weiss \& Amorose, 2005). Young children may not possess the cognitive skills to distinguish correctly between actual gross motor competence, ability, and effort (Harter, 1999; Jacobs, Lanza, Osgood, Eccles, \& Wigfield, 2002). Children in this study had high positive perceptions of their competence, consistent with ranges previously reported in the literature for preschool children (LeGear et al., 2012). These positive perceptions of self-competence at this early age can be important because children with high perceived motor competence exhibit higher self-esteem, exert greater effort, and will probably select tasks that further challenge their ability (Weiss \& Amorose, 2005).

As we anticipated, moderate to vigorous PA was not predicted by the perceived motor competence of children, and we found no association or effect at all. Fellow researchers have found the same results in children of similar ages (Barnett, Ridgers, \& Salmon, 2015; Robinson, Wadsworth, \& Peoples, 2012). In older children between the ages of 8 and 12 years, studies have found a direct association between perceived motor competence and PA participation. For example, Carroll and Loumidis (2001) found that children with high perceived motor competence participated significantly more in PA outside of school than those with low perceived motor competence, and Barnett et al. (2011) found that perceived sport competence in adolescents acted as a mediator between gross motor competence and PA.

In terms of sedentary behavior, there is little available evidence from which to draw. In older children, a recent review of determinants of sedentary behavior in young people found no articles that addressed perceived motor competence as a determinant of sedentary behavior (Uijtdewilligen et al., 2011). This might suggest that other factors aside from perceived motor competence are more important for young children's sedentary behavior, although there is a need for more research in this area to confirm this.

In the case of the association between gross motor competence and PA, we did not find any effect in our study, despite this effect's being relatively well established in the literature for older children (Barnett et al., 2013; Lubans et al., 2010). An answer can be that the association may increase with age. In early childhood, associations tend to be low: For instance, Fisher et al. (2005) found a weak association (.02-.18) in preschool children between gross motor competence and PA (total PA, moderate to vigorous PA and light-intensity PA). Across middle and late childhood, associations tend to be moderate and strong. For example, Castelli and Valley (2007) found in children ages 7-12 years a correlation of .55 between gross motor competence and PA. Similarly, Raudsepp and Päll (2006) found developmental levels of both overhand throwing and jumping were significantly correlated with skill-specific PA ( $r \mathrm{~s}=.44-.55)$ assessed with an observational method. However, in this same study, when PA was assessed with an objective method (Caltrac accelerometer), PA was not significantly related to jumping and overhand throwing skills. Interestingly, one recent study also found no relationship between gross motor competence and PA in 8-year-old children as measured by accelerometry (Barnett, Zask, Rose, Hughes, \& Adams, 2015). In this study, children were also very active on average, perhaps limiting the ability to distinguish activity differences between children of higher or lower skill. These studies highlight methodological issues with identifying relationships among these variables (Slykerman, Ridgers, Stevenson, \& Barnett, 2016). 
The association between gross motor competence and sedentary behavior has been less considered. Meanwhile, accumulating evidence has suggested that, independent of PA levels, sedentary behavior is associated with increased risk of cardiometabolic disease and a variety of physiological and psychological problems (Tremblay et al., 2011). For instance, watching TV for more than $2 \mathrm{hr}$ per day was associated with unfavorable body composition, decreased fitness, lowered scores for self-esteem and prosocial behavior, and decreased academic achievement in school-age children and youths (ages 5-17 years; Tremblay et al., 2011). The few studies that have analyzed the association between sedentary behavior and gross motor competence in young children also found no relationship (Cliff et al., 2009; Graf et al., 2004). In older children, Wrotniak et al. (2006) found significant negative associations between time in sedentary behavior and gross motor competence. Similarly, L. Lopes, Santos, Pereira, and Lopes (2012) found that time in sedentary behavior significantly discriminated between children with low and high motor coordination. This further reinforces the idea that these relationships become more important with developmental age (Stodden et al., 2008). Our study confirms these yet incipient relationships at this early stage of life and the need to further look into developmental age to identify the possible cornerstone element that can trigger individual motor development.

The cross-sectional design of the current study did not allow us to identify the age and factors of changes in the relationships, and this is a limitation. The novelty of this study is the consideration of gross motor competence and perceived motor competence in relation to both moderate to vigorous PA and sedentary behavior. The findings provide further evidence that relationships between these variables probably emerge later in childhood. The strengths of this study are the objective measurement of PA and sedentary behavior and the use of a validated assessment tool for both gross motor competence and perceived motor competence. A limitation is that for the perceived motor competence index, items were summed from two separate factor scales, but this made logical sense for the research questions in this study. Similar to other motor assessments (Körperkoordinationstest für Kinder [Kiphard \& Schilling, 1974], Peabody Developmental Motor Scales [Folio $\&$ Fewell, 2000]), the MABC-2 was designed to measure motor impairment, and therefore this may be a design limitation in terms of discriminating among typically developing children. However, the manual of the edition we used states that, unlike the previous edition, standard scores and percentiles are provided in addition to impairment scores, thus broadening the applicability of this instrument (Henderson et al., 2007). In conclusion, in attempting to increase PA and reduce sedentary behavior in this age group, other factors aside from gross motor competence and perceived motor competence appear to be of more importance as correlates. However, because this age period is a crucial time for developing motor competence (Gabbard, 2011) and because there is mounting evidence that motor competence will become important in subsequent years to health behaviors, efforts should still be spent on programs to enhance motor competence in the early years.

\section{Acknowledgments}

There was no financial assistance with this project. Lisa Barnett is supported by an Alfred Deakin fellowship. 


\section{References}

Babic, M., Morgan, P., Plotnikoff, R., Lonsdale, C., White, R., \& Lubans, D. (2014). Physical activity and physical self-concept in youth: Systematic review and meta-analysis. Sports Medicine, 44, 1589-1601. doi:10.1007/s40279-014-0229-z

Barnett, L.M., Hardy, L.L., Lubans, D.R., Cliff, D.P., Okely, A.D., Hills, A.P., \& Morgan, P.J. (2013). Australian children lack the basic movement skills to be active and healthy. Health Promotion Journal of Australia, 24, 82-84. doi:10.1071/HE12920

Barnett, L.M., Morgan, P.J., van Beurden, E., Ball, K., \& Lubans, D.R. (2011). A reverse pathway? Actual and perceived skill proficiency and physical activity. Medicine and Science in Sports and Exercise, 43, 898-904. doi:10.1249/MSS.0b013e3181fdfadd

Barnett, L.M., Morgan, P., van Beurden, E., \& Beard, J. (2008). Perceived sports competence mediates the relationship between childhood motor skill proficiency and adolescent physical activity and fitness: A longitudinal assessment. International Journal of Behavioral Nutrition and Physical Activity, 5(1), 40. doi:10.1186/1479-5868-5-40

Barnett, L.M., Ridgers, N.D., \& Salmon, J. (2015). Associations between young children's perceived and actual ball skill competence and physical activity. Journal of Science and Medicine in Sport, 18, 167-171. doi:10.1016/j.jsams.2014.03.001

Barnett, L.M., van Beurden, E., Morgan, P.J., Brooks, L.O., \& Beard, J.R. (2009). Childhood motor skill proficiency as a predictor of adolescent physical activity. Journal of Adolescent Health, 44, 252-259. doi:10.1016/j.jadohealth.2008.07.004

Barnett, L.M., Zask, A., Rose, L., Hughes, D., \& Adams, J. (2015). Three year follow-up of an early childhood intervention: What about physical activity and weight status? Journal of Physical Activity and Health, 12, 319-321. doi:10.1123/jpah.2013-0419

Cain, K.L., Sallis, J.F., Conway, T.L., Dyck, D.V., \& Calhoon, L. (2013). Using accelerometers in youth physical activity studies: A review of methods. Journal of Physical Activity and Health, 10, 437-450.

Carroll, B., \& Loumidis, J. (2001). Children's perceived competence and enjoyment in physical education and physical activity outside school. European Physical Education Review, 7(1), 24-43. doi:10.1177/1356336X010071005

Castelli, D., \& Valley, J. (2007). The relationship of physical fitness and motor competence to physical activity. Journal of Teaching in Physical Education, 26, 358-374.

Cliff, D.P., Okely, A.D., Smith, L.M., \& McKeen, K. (2009). Relationships between fundamental movement skills and objectively measured physical activity in preschool children. Pediatric Exercise Science, 21, 436-449.

Cole, T., Bellizzi, M., Flegal, K., \& Dietz, W. (2000). Establishing a standard definition for child overweight and obesity worldwide: International survey. BMJ, 320, 1240-1244. doi:10.1136/bmj.320.7244.1240

Cole, T.J., Flegal, K.M., Nicholls, D., \& Jackson, A.A. (2007). Body mass index cut offs to define thinness in children and adolescents: International survey. BMJ, 335, 194-197. doi:10.1136/bmj.39238.399444.55

Ducharne, M.A.B. (2004). Avaliação da auto-percepção de competência: Adaptação da PSPCSA numa população portuguesa [Evaluation of self-perceived competence: A Portuguese adaptation of the PSPCSA. Psico-USF, 9, 137-145.

Eston, R., \& Reilly, T.E. (Eds.). (2001). Kinanthropometry and exercise physiology laboratory manual: Tests, procedures and data: Vol. 2. Anthropometry (2nd ed.). London, England: Routledge.

Fisher, A., Reilly, J.J., Kelly, L.A., Montgomery, C., Williamson, A., Paton, J.Y., \& Grant, S. (2005). Fundamental movement skills and habitual physical activity in young children. Medicine and Science in Sports and Exercise, 37, 684-688. doi:10.1249/01. MSS.0000159138.48107.7D

Folio, M.R., \& Fewell, R.R. (2000). Peabody Developmental Motor Scales (PDMS-2) (5th ed.). Austin, TX: Pro-Ed. 
Gabbard, C. (2011). Lifelong Motor Development. San Francisco, CA: Benjamin Cummings.

Goodway, J.D., \& Rudisill, M.E. (1997). Perceived physical competence and actual motor skill competence of African American preschool children. Adapted Physical Activity Quarterly, 14, 314-326.

Goodway, J.D., \& Smith, D.W. (2005). Keeping all children healthy: Challenges to leading an active lifestyle for preschool children qualifying for at-risk programs. Family \& Community Health, 28, 142-155. doi:10.1097/00003727-200504000-00006

Graf, C., Koch, B., Dordel, S., Schindler-Marlow, S., Icks, A., Schüller, A., . . Predel, H.-G. (2004). Physical activity, leisure habits and obesity in first-grade children. European Journal of Cardiovascular Prevention and Rehabilitation, 11, 284-290. doi:10.1097/01. hjr.0000129740.30593.18

Harter, S. (1999). The construction of the self: A developmental perspective. New York, NY: Guilford Press.

Harter, S., \& Pike, R. (1984). The pictorial scale of perceived competence and social acceptance for young children. Child Development, 55, 1969-1982. doi:10.2307/1129772

Henderson, S.E., Sugden, D.A., \& Barnett, A. (2007). Movement Assessment Battery for Children-2 examiner's manual. London, England: Harcourt Assessment.

Jacobs, J.E., Lanza, S., Osgood, D.W., Eccles, J.S., \& Wigfield, A. (2002). Changes in children's self-competence and values: Gender and domain differences across Grades One through Twelve. Child Development, 73, 509-527. doi:10.1111/1467-8624.00421

Janssen, X., Cliff, D.P., Reilly, J.J., Hinkley, T., Jones, R.A., Batterham, M., . . Okely, A.D. (2013). Predictive validity and classification accuracy of ActiGraph energy expenditure equations and cut-points in young children. PLoS One, 8(11), e79124. doi:10.1371/ journal.pone.0079124

Kiphard, E.J., \& Schilling, F. (1974). Körperkoordinationstest für Kinder: KTK Manual. Weinheim, Germany: Beltz Test GmbH.

LeBlanc, A.G., Spence, J.C., Carson, V., Connor Gorber, S., Dillman, C., Janssen, I., . . . Tremblay, M.S. (2012). Systematic review of sedentary behaviour and health indicators in the early years (aged 0-4 years). Applied Physiology, Nutrition, and Metabolism, 37, 753-772. doi:10.1139/h2012-063

LeGear, M., Greyling, L., Sloan, E., Bell, R., Williams, B.-L., Naylor, P.-J., \& Temple, V. (2012). A window of opportunity? Motor skills and perceptions of competence of children in kindergarten. International Journal of Behavioral Nutrition and Physical Activity, 9(1), 29. doi:10.1186/1479-5868-9-29

Lopes, L., Santos, R., Pereira, B., \& Lopes, V. P. (2012). Associations between sedentary behavior and motor coordination in children. American Journal of Human Biology, 24, 746-752. doi:10.1002/ajhb.22310

Lopes, V.P., Rodrigues, L.P., Maia, J.A.R., \& Malina, R.M. (2011). Motor coordination as predictor of physical activity in childhood. Scandinavian Journal of Medicine \& Science in Sports, 21, 663-669. doi:10.1111/j.1600-0838.2009.01027.x

Lubans, D.R., Morgan, P.J., Cliff, D.P., Barnett, L.M., \& Okely, A.D. (2010). Fundamental movement skills in children and adolescents: Review of associated health benefits. Sports Medicine, 40, 1019-1035. doi:10.2165/11536850-000000000-00000

Pate, R.R., O'Neill, J.R., \& Lobelo, F. (2008). The evolving definition of “sedentary." Exercise and Sport Sciences Reviews, 36, 173. doi:10.1097/JES.0b013e3181877d1a

Raudsepp, L., \& Päll, P. (2006). The relationship between fundamental motor skills and outside-school physical activity of elementary school children. Pediatric Exercise Science, 18, 426-435.

Robinson, L.E. (2011). The relationship between perceived physical competence and fundamental motor skills in preschool children. Child: Care, Health and Development, 37, 589-596.

Robinson, L.E., Wadsworth, D.D., \& Peoples, C.M. (2012). Correlates of school-day physical activity in preschool students. Research Quarterly for Exercise and Sport, 83(1), 20-26. doi:10.1080/02701367.2012.10599821 
Schulz, J., Henderson, S.E., Sugden, D.A., \& Barnett, A.L. (2011). Structural validity of the Movement ABC-2 test: Factor structure comparisons across three age groups. Research in Developmental Disabilities, 32, 1361-1369. doi:10.1016/j.ridd.2011.01.032

Slykerman, S., Ridgers, N.D., Stevenson, C., \& Barnett, L.M. (2016). How important is young children's actual and perceived movement skill competence to their physical activity? Journal of Science and Medicine in Sport, 19, 488-492. doi:10.1016/j. jsams.2015.07.002

Spessato, B.C., Gabbard, C., Robinson, L., \& Valentini, N.C. (2013). Body mass index, perceived and actual physical competence: The relationship among young children. Child: Care, Health and Development, 39, 845-850.

Stodden, D. F., Goodway, J. D., Langendorfer, S. J., Robertson, M. A., Rudisill, M. E., Garcia, C., \& Garcia, L. E. (2008). A developmental perspective on the role of motor skill competence in physical activity: An emergent relationship. Quest, 60, 290-306. doi:10.1080/00336297.2008.10483582

Tremblay, M., LeBlanc, A., Kho, M., Saunders, T., Larouche, R., Colley, R., . . . Gorber, S. (2011). Systematic review of sedentary behaviour and health indicators in school-aged children and youth. International Journal of Behavioral Nutrition and Physical Activity, 8(1), 98. doi:10.1186/1479-5868-8-98

Uijtdewilligen, L., Nauta, J., Singh, A.S., van Mechelen, W., Twisk, J.W.R., van der Horst, K., \& Chinapaw, M.J.M. (2011). Determinants of physical activity and sedentary behaviour in young people: A review and quality synthesis of prospective studies. British Journal of Sports Medicine, 45, 896-905. doi:10.1136/bjsports-2011-090197

Vedul-Kjelsås, V., Sigmundsson, H., Stensdotter, A.K., \& Haga, M. (2012). The relationship between motor competence, physical fitness and self-perception in children. Child: Care, Health and Development, 38, 394-402.

Weiss, M.R., \& Amorose, A.J. (2005). Children's self-perceptions in the physical domain: Between- and within-age variability in level, accuracy, and sources of perceived competence. Journal of Sport \& Exercise Psychology, 27, 226-244.

Wrotniak, B. H., Epstein, L. H., Dorn, J. M., Jones, K. E., \& Kondilis, V. A. (2006). The relationship between motor proficiency and physical activity in children. Pediatrics, 118, e1758-e1765. doi:10.1542/peds.2006-0742 